\title{
DEMANDAS DE ATENÇÃO DO ENFERMEIRO EM UNIDADE DE TERAPIA INTENSIVA NEONATAL, PEDIÁTRICA E GERAL
}

Danilo Marcelo Araujo dos Santos ${ }^{1}$, Francisca Georgina Macedo de Sousa ${ }^{2}$, Thaís Marques Moreira ${ }^{3}$, Andréa Cristina Oliveira Silva², Lorena Carvalho Braga ${ }^{4}$

${ }^{1}$ Enfermeiro. Mestre em Enfermagem. Hospital Universitário da Universidade Federal do Maranhão. São Luís, MA, Brasil. ${ }^{2}$ Enfermeira. Doutora em Enfermagem. Docente da Universidade Federal do Maranhão. São Luís, MA, Brasil.

${ }^{3}$ Enfermeira. Enfermeira Administrativa do Vidas Resgate e Home Care. São Luís, MA, Brasil.

${ }^{4}$ Enfermeira. Residente do Hospital Universitário da Universidade Federal do Maranhão. São Luís, MA, Brasil.

RESUMO: Estudo descritivo quantitativo com objetivo de identificar demandas de atenção do enfermeiro intensivista e o esforço depreendido por este profissional para lidar com estas demandas. A pesquisa foi desenvolvida em três contextos da terapia intensiva (pediátrica, neonatal e geral) de um hospital do nordeste brasileiro. Participaram da pesquisa 34 enfermeiros com exercício profissional em uma das Unidades de Terapia Intensiva. Os dados foram coletados no período de maio de 2011 a junho de 2012, apoiado pelo instrumento Demandas de Atenção Dirigida. As demandas que mais exigiram atenção do enfermeiro concentram-se no Domínio Ambiente Físico e Psicológico e estavam associadas às instalações físicas do ambiente de trabalho, às emoções e preocupações do enfermeiro nas relações assistenciais. Os resultados sugerem estabelecimento de intervenções no ambiente, na estrutura e nas práticas de cuidado com vistas a favorecer melhor qualidade da assistência e de vida dos enfermeiros.

DESCRITORES: Enfermagem; Unidades de terapia intensiva; Cuidado intensivo.

\section{NURSING ATTENTION DEMANDS AT A NEONATAL, PEDIATRIC AND GENERAL INTENSIVE CARE UNIT}

ABSTRACT: Descriptive and quantitative study to identify intensive nursing attention demands and the efforts these professionals make to cope with these demands. The research was developed in three intensive care contexts (pediatric, neonatal and general) at a hospital in the Brazilian Northeast. The data were collected between May 2011 and June 2012, based on the tool Directed Attention Demands. The demands that most required nursing attention are concentrated in the Domain Physical and Psychological Environment and were associated with the physical facilities of the work environment, with the nurse's emotions and concerns in the care relations. The results suggest the establishment of interventions in the environment, in the structure and in the care practices with a view to favoring a better quality of care and quality of life for the nurses.

DESCRIPTORS: Nursing; Intensive care units; Intensive care.

\section{DEMANDAS DE ATENCIÓN DEL ENFERMERO EN UNIDAD DE TERAPIA INTENSIVA NEONATAL, PEDIÁTRICA Y GENERAL}

RESUMEN: Estudio descriptivo cuantitativo con objetivo de identificar demandas de atención del enfermero intensivista y el esfuerzo hecho por ese profesional para trabajar con esas demandas. La investigación fue desarrollada en tres contextos de terapia intensiva (pediátrica, neonatal y general) de un hospital del nordeste brasileño. Participaron de la investigación 34 enfermeros con ejercicio profesional en una de las Unidades de Terapia Intensiva. Los datos fueron obtenidos en el periodo de mayo de 2011 a junio de 2012, apoyado por el instrumento Demandas de Atención Dirigida. Las demandas que más exigieron atención del enfermero se concentran en el Dominio Ambiente Físico y Psicológico y estaban asociadas a las instalaciones físicas del ambiente de trabajo, a las emociones y preocupaciones del enfermero en las relaciones asistenciales. Los resultados sugieren establecimiento de intervenciones en el ambiente, en la estructura y en las prácticas de cuidado con fines de favorecer más cualidad de la asistencia y de vida de los enfermeros.

DESCRIPTORES: Enfermería; Unidades de terapia intensiva; Cuidado intensivo. 


\section{INTRODUÇÃO}

No contexto da Unidade de Terapia Intensiva (UTI), o trabalho do enfermeiro é permeado por múltiplas demandas de atenção provenientes da complexidade e prestação dos cuidados, do ambiente de trabalho e da própria instituição de saúde ${ }^{(1)}$. Essas demandas são situações que exigem do enfermeiro competências técnicas e atitudinais para conduzir a assistência de forma ágil, segura e precisa.

O uso da atenção no trabalho do enfermeiro é essencial para a realização das suas atividades diárias, que envolvem tanto o planejamento como a prestação do cuidado a pacientes, incluindo aqueles com risco iminente de morte ${ }^{(2)}$. Além dessas atribuições, a autora destaca que cabe ao enfermeiro coordenar as atividades do setor, mesmo frente a fatores como ruído excessivo, iluminação intensa, sobrecarga de trabalho e conflitos. São condições que requerem do enfermeiro maior Capacidade para Direcionar Atenção (CDA) que diz respeito à habilidade do indivíduo em inibir estímulos e distrações competitivas, tanto do ambiente interno como do ambiente externo, enquanto processa e organiza uma informação importante, condição que requer o uso de esforço mental ${ }^{(3)}$. A atenção é compreendida como a concentração da mente em um objeto ou pensamento, apesar de vários outros estímulos ocorrerem simultaneamente ${ }^{(2)}$.

$\mathrm{Na}$ prática diária, o enfermeiro de UTI deve direcionar sua atenção para múltiplas e, frequentemente, competitivas demandas impostas pela grande variedade de estímulos no ambiente, enquanto presta assistência aos pacientes e seus familiares, ao mesmo tempo em que se relaciona com colegas e outros profissionais( ${ }^{(2)}$. A exposição constante do enfermeiro a essas fontes de demandas de atenção pode ocasionar fadiga, que é notada pela redução da CDA, podendo refletir no planejamento e na implementação da assistência ${ }^{(1)}$. Dessa maneira, é importante refletir sobre a questão que permitiu conduzir a pesquisa: Quais as demandas de atenção do enfermeiro nos contextos da terapia intensiva pediátrica, neonatal e geral? Qual o esforço depreendido pelos enfermeiros em cada demanda de atenção?

Partindo destes questionamentos, asseverase que a avaliação dessas demandas de trabalho, bem como dos fatores associados a ela, tem se mostrado indispensável como recurso para a gestão das unidades. Nessas circunstâncias, uma equipe de enfermagem com o conhecimento prévio dos fatores associados à alta carga de trabalho é capaz de estabelecer estratégias para admitir o paciente na unidade e dar continuidade ao processo de cuidar, de modo a garantir a qualidade e a eficiência da sua função. Portanto, o conhecimento dos fatores associados à carga de trabalho de enfermagem é um recurso fundamental para o enfermeiro em sua prática na $\mathrm{UTI}^{(4)}$. Dessa maneira, a atenção, somada ao conhecimento técnico e científico, é essencial para que o enfermeiro possa, no exercício da profissão, lidar eficazmente com as demandas de alta complexidade e especialidade que seu trabalho requer ${ }^{(5)}$.

Desse modo, desenvolver uma investigação com essa temática concorre para a compreensão do processo de trabalho do enfermeiro na UTI, contribuindo para o planejamento do cuidado com vistas a atender às demandas de atenção de pacientes e famílias.

A pesquisa teve como objetivo identificar as demandas de atenção do Enfermeiro nos contextos da UTI Pediátrica, Neonatal e Geral, assim como o esforço depreendido para lidar com estas demandas.

\section{METODOLOGIA}

Trata-se de estudo transversal, prospectivo, descritivo, de abordagem quantitativa, desenvolvido em três UTIs (Pediátrica, Neonatal e Geral) de um Hospital Universitário da região nordeste do Brasil.

Participaram da pesquisa 34 enfermeiros, dos quais nove desenvolviam suas atividades profissionais na UTI Pediátrica, 15 na UTI Neonatal e 10 na UTI Geral. Estabeleceu-se como critério de inclusão ser enfermeiro e estar em exercício profissional na unidade há, no mínimo, seis meses. Foram excluídos dois enfermeiros que estavam em gozo de licença médica no período da coleta de dados.

A coleta de dados foi realizada no período de maio de 2011 a junho de 2012, utilizando-se o instrumento Demandas de Atenção Dirigida - RDA, validado e adaptado à cultura brasileira, cuja finalidade é identificar as diferentes fontes de demandas de atenção a que o enfermeiro está exposto em seu ambiente de trabalho ${ }^{(1)}$. Este instrumento é composto por 39 itens agrupados nos domínios: Psicológico, Comportamental e Ambiente Físico.

O domínio Psicológico possui 12 itens, os 
quais envolvem emoções e preocupações que funcionam como fonte de distração para o profissional. O domínio Comportamental é composto por 13 itens de natureza física, social ou situacional que interferem ou restringem a capacidade da pessoa direcionar a atenção. O domínio Ambiente Físico contém 14 itens que abordam fatores no ambiente externo que exigem do profissional aumento do esforço mental para realizar determinada atividade.

Cada item do instrumento possui dois tipos de medidas: a primeira questiona sobre a frequência com que se vivenciou determinada situação, representada por uma escala do tipo Likert com as seguintes alternativas de resposta: "nenhuma vez", "raramente" "poucas/algumas vezes", "ocasionalmente/moderadamente" e "muitas vezes/o tempo todo" com pontuação que varia de zero a quatro.

A segunda medida refere-se à intensidade, ou seja, o quanto de esforço mental foi necessário para lidar com aquela situação. Para tanto, utilizouse de escala analógica visual de zero a $100 \mathrm{~mm}$, com dois extremos (sem esforço/nada exigente e extremo esforço/extremamente exigente), ou seja, quanto maior for o esforço exigido pela situação maior será a pontuação.

O formulário foi entregue por um dos pesquisadores a cada um dos profissionais participantes da pesquisa no seu horário e ambiente de trabalho. Nessa oportunidade foi acordado dia e horário para a devolução. Aqueles que, por algum motivo, não devolveram nessa oportunidade, foi agendada nova data de forma que coincidisse com o plantão subsequente do profissional.

Os dados coletados foram inseridos em planilha do Microsoft Excel 2010 segundo cada UTI. Para análise, utilizou-se estatística descritiva, considerando-se primeiramente a frequência e a intensidade de cada demanda. A pontuação total de cada situação de demanda foi obtida multiplicando o valor da frequência pela intensidade. Para a obtenção da Média Aritmética ('x) das situações de demandas, multiplicou-se o somatório $(\Sigma)$ da frequência pelo somatório $\left(\sum\right)$ da intensidade dividido pelo número de enfermeiros $(n)$, podendo ser obtido um resultado entre zero e 400. Os resultados da pesquisa estão apresentados a partir das médias obtidas em cada situação de demanda. A fórmula utilizada para alcance das médias da pontuação de demandas foi a seguinte:

$$
\bar{x}=\frac{\left(\sum \text { frequência }\right) x(\text { (intensidade })}{n}
$$

Foram consideradas como demandas que exigiram maior atenção do enfermeiro aquelas com média igual ou maior que 60 . As demandas com média inferior a 60 foram definidas como aquelas que exigiram menos atenção desse profissional nas suas atividades na UTI.

A análise dos dados foi realizada sob duas perspectivas, a primeira a partir da média da pontuação das demandas (frequência versus intensidade) e a segunda levando em consideração somente a média da intensidade. Optou-se por essa estratégia por julgar que no cotidiano da UTI alguns procedimentos/técnicas, embora realizados com maior frequência, exigem menos atenção do enfermeiro. Por outro lado, há no processo de cuidar, situações menos frequentes que exigem do enfermeiro maior demanda de atenção, como a morte de um paciente ou a reanimação cardiopulmonar.

Estapesquisafazpartedoprojeto"Necessidades de Familiares de Pacientes Internados e Demandas de Atenção do Enfermeiro em Unidade de Terapia Intensiva", aprovada pelo Comitê de Ética em Pesquisa do Hospital Universitário da Universidade Federal do Maranhão sob o Parecer 092/11 de 06 de maio de 2011. Os enfermeiros que atenderam aos critérios de inclusão foram convidados a participar da pesquisa e solicitados a assinar o Termo de Consentimento Livre e Esclarecido. Toda a pesquisa foi conduzida de forma a obedecer todos os aspectos éticos exigidos pela legislação brasileira.

\section{RESULTADOS}

Na Tabela 1 estão apresentadas as situações de demandas que mais exigiram atenção dos enfermeiros e na Tabela 2 as menos exigentes, ambas organizadas em ordem decrescente da média aritmética $\left({ }^{-} \mathrm{x}\right)$ considerando frequência versus intensidade das três unidades de cuidados intensivos. Nas colunas subsequentes das tabelas estão apresentadas as médias aritméticas por unidade, a média da intensidade e a frequência relativa de cada demanda das três unidades.

Quando considerados os domínios do instrumento RDA e a média da frequência versus intensidade, as demandas do ambiente físico e do psicológico obtiveram as maiores médias. Tais domínios desenvolvem situações associadas 
Tabela 1 - Situações de demandas que mais exigiram a atenção do enfermeiro considerando a média geral, as médias por UTI, a média da intensidade e a frequência relativa. São Luís, MA, Brasil, 2012

\begin{tabular}{|c|c|c|c|c|c|c|c|c|c|}
\hline \multirow[t]{3}{*}{ Situações de Demandas } & \multirow[t]{3}{*}{$\mathbf{D}^{*}$} & \multicolumn{4}{|c|}{$\begin{array}{l}\text { Pontuação da Demanda } \\
\text { (Frequência x Intensidade) }\end{array}$} & \multirow[t]{3}{*}{$\begin{array}{l}\text { Intensi- } \\
\text { dade }\end{array}$} & \multicolumn{3}{|c|}{ Frequência (\%) } \\
\hline & & \multirow[t]{2}{*}{ Geral } & UTI & UTI & UTI & & \multirow[t]{2}{*}{0 dia } & \multirow{2}{*}{$\begin{array}{c}1-2 \\
\text { dias }\end{array}$} & \multirow{2}{*}{$\begin{array}{l}\geq 3 \\
\text { dias }\end{array}$} \\
\hline & & & Ped & Neo & Geral & & & & \\
\hline Alto nível de barulho na unidade & $\mathrm{F}$ & 261,8 & 342,4 & 199,2 & 243,7 & 72,1 & 4,4 & 4,4 & 91,1 \\
\hline $\begin{array}{l}\begin{array}{l}\text { Observar o sofrimento de um } \\
\text { paciente }\end{array} \\
\end{array}$ & $\mathrm{P}$ & 216 & 253,6 & 162,4 & 232,1 & 63,9 & 4,4 & 29,9 & 65,3 \\
\hline $\begin{array}{l}\text { Execução de procedimentos que os } \\
\text { pacientes experenciam como sendo } \\
\text { dolorosos }\end{array}$ & $P$ & 184,4 & 256,2 & 164,7 & 132,2 & 56,1 & 4,4 & 43,2 & 52 \\
\hline $\begin{array}{l}\text { Ambiente de trabalho abarrotado de } \\
\text { materiais e equipamentos }\end{array}$ & $\mathrm{F}$ & 165,8 & 246,1 & 77,4 & 173,9 & 50,7 & 14,4 & 34,7 & 50,5 \\
\hline $\begin{array}{l}\text { Pessoas demais em sua unidade de } \\
\text { trabalho }\end{array}$ & $\mathrm{F}$ & 165,7 & 152,3 & 71,7 & 273,1 & 50,7 & 26,5 & 21,8 & 51,3 \\
\hline $\begin{array}{l}\text { Sentimento de impotência diante } \\
\text { de um paciente que não consegue } \\
\text { melhorar }\end{array}$ & $\mathrm{P}$ & 163 & 190,4 & 143,7 & 154,8 & 57,5 & 9,2 & 43,2 & 47,2 \\
\hline $\begin{array}{l}\text { Quadro de funcionários insuficiente } \\
\text { para cobrir a unidade adequadamente }\end{array}$ & $\mathrm{F}$ & 149,3 & 92,4 & 138,7 & 216,9 & 53,3 & 9,5 & 43,4 & 46,7 \\
\hline $\begin{array}{l}\text { Necessidade de dar orientação à } \\
\text { família }\end{array}$ & $\mathrm{P}$ & 135,3 & 217,1 & 89,1 & 99,8 & 39,7 & 10 & 22,1 & 67,5 \\
\hline $\begin{array}{l}\text { Muitas decisões rápidas tiveram que } \\
\text { ser tomadas }\end{array}$ & $\mathrm{F}$ & 132,5 & 168,8 & 98,6 & 130 & 42,9 & 4,4 & 41 & 54,2 \\
\hline $\begin{array}{l}\text { Cuidar de famílias com necessidades } \\
\text { emocionais }\end{array}$ & $\mathrm{P}$ & 121,2 & 155,3 & 117,7 & 90,6 & 46 & 19,2 & 41,7 & 38,8 \\
\hline $\begin{array}{l}\text { Quadro de funcionários e escala de } \\
\text { trabalho imprevisíveis }\end{array}$ & $\mathrm{F}$ & 115 & 118 & 66,5 & 160,6 & 42,4 & 25,4 & 40,2 & 34 \\
\hline $\begin{array}{l}\text { Foram requeridas tarefas que não são } \\
\text { de enfermagem, tais como trabalho } \\
\text { burocrático }\end{array}$ & $\mathrm{F}$ & 108,5 & 207,7 & 50,4 & 67,3 & 31,7 & 33,5 & 42,4 & 23,7 \\
\hline $\begin{array}{l}\text { Tempo insuficiente para dar apoio } \\
\text { emocional a um paciente }\end{array}$ & $\mathrm{F}$ & 98,5 & 33,8 & 67,2 & 194,4 & 36,5 & 31,7 & 33,5 & 34,4 \\
\hline $\begin{array}{l}\text { Medo de cometer um erro ao cuidar } \\
\text { de um paciente }\end{array}$ & $\mathrm{P}$ & 95,6 & 179,9 & 45,2 & 61,6 & 45,4 & 21,4 & 67,2 & 11 \\
\hline $\begin{array}{l}\text { Ambiente de trabalho confuso ou } \\
\text { desorganizado }\end{array}$ & $\mathrm{F}$ & 88,5 & 140,4 & 45,3 & 79,8 & 43,4 & 14,8 & 70,9 & 14 \\
\hline $\begin{array}{l}\text { Tempo insuficiente para completar } \\
\text { todas as suas tarefas de enfermagem }\end{array}$ & $\mathrm{F}$ & 86,6 & 49,2 & 104,7 & 105,9 & 37,2 & 29,2 & 71,5 & 18,9 \\
\hline $\begin{array}{l}\text { Cuidar de pacientes que necessitavam } \\
\text { de intenso apoio emocional }\end{array}$ & $P$ & 82 & 61 & 74,8 & 110,2 & 30,2 & 39,8 & 25,9 & 34 \\
\hline $\begin{array}{l}\text { Múltiplas atividades de enfermagem } \\
\text { tiveram que ser completadas }\end{array}$ & $\mathrm{F}$ & 77,8 & 38,3 & 78,4 & 116,8 & 30,4 & 14,8 & 36,5 & 52 \\
\hline A morte de um paciente & $\mathrm{P}$ & 73,3 & 54,9 & 28,3 & 136,8 & 38 & 41,3 & 38,3 & 20 \\
\hline $\begin{array}{l}\text { Não saber o que dizer a um paciente } \\
\text { ou ao seu familiar sobre a condição } \\
\text { do mesmo }\end{array}$ & $\mathrm{C}$ & 63,1 & 78 & 87,8 & 23,6 & 34,4 & 46,1 & 42,9 & 10,7 \\
\hline
\end{tabular}


às instalações físicas do ambiente de trabalho, às emoções e preocupações, o que exige do enfermeiro maior capacidade de direcionar sua atenção para a prestação do cuidado ${ }^{(6)}$.

Das 14 demandas do Domínio Físico do RDA, 11 delas $(78,6 \%)$ exigiram maior atenção do enfermeiro em UTI. Dentre elas, enfatiza-se o alto nível de barulho ( $(x=261,8)$; ambiente de trabalho abarrotado de materiais e equipamentos ( $\left.{ }^{-} \mathrm{x}=165,8\right)$; pessoas demais em uma unidade de trabalho $\left({ }^{-} \mathrm{x}=165,7\right)$; quadro de funcionários insuficientes para cobrir a unidade adequadamente $\left({ }^{-} \mathrm{x}=149,3\right)$; muitas decisões rápidas tiveram que ser tomadas $\left({ }^{-} \mathrm{x}=132,5\right)$; quadro de funcionários e escala de trabalho imprevisíveis $\left({ }^{-} \mathrm{x}=115,0\right)$; foram requeridas tarefas que não são de enfermagem tais como o trabalho burocrático $\left({ }^{-} \mathrm{x}=108,5\right)$; e tempo insuficiente para dar apoio emocional a um paciente $\left({ }^{-} \mathrm{x}=98,5\right)$.

Dos 12 itens do Domínio Psicológico, quatro deles $(33,3 \%)$ obtiveram as maiores médias: observar o sofrimento de um paciente $\left({ }^{-} \mathrm{x}=216,0\right)$; execução de procedimentos que os pacientes experenciaram como sendo dolorosos $\left({ }^{-} \mathrm{x}=184,4\right)$; sentimento de impotência diante de um paciente que não consegue melhorar $\left({ }^{-} x=163,0\right)$; e necessidade de dar orientação à família $\left({ }^{-} \mathrm{x}=135,3\right)$.

As demandas do Domínio Comportamental apresentaram médias inferiores às dos Domínios Físico e Psicológico, e, somente "não saber o que dizer a um paciente ou ao seu familiar sobre as condições do mesmo" $\left({ }^{-} x=63,1\right)$ surge entre as maiores demandas.

Quando considerada a intensidade isoladamente, as demandas que mais exigiram atenção do enfermeiro em UTI foram: alto nível de barulho na unidade (Domínio Ambiente Físico); observar o sofrimento de um paciente (Domínio Psicológico); sentimento de impotência diante de um paciente que não consegue melhorar (Domínio Psicológico); execução de procedimentos que os pacientes experenciam como sendo dolorosos (Domínio Psicológico) e quadro de funcionários insuficiente para cobrir a unidade adequadamente (Domínio Ambiente Físico).

O alto nível de barulho na unidade, a necessidade de dar orientação à família e observar o sofrimento de um paciente foram apontadas pelos enfermeiros como as demandas de maior frequência cuja ocorrência foi igual ou maior a três dias por semana.

Considerando-se cada unidade, a demanda alto nível de barulho na unidade foi a principal causa de aumento do esforço mental dos enfermeiros nas UTIs Pediátrica e Neonatal sendo que na UTI Pediátrica obteve média $\left({ }^{-} \mathrm{x}=342,4\right)$ mais elevada que na UTI Neonatal $\left({ }^{-} \mathrm{x}=199,2\right)$. Na UTI Geral, essa demanda foi a segunda mais exigente com média $\left({ }^{-} \mathrm{x}=243,7\right)$ maior que na UTI Neonatal.

Ao considerar as cinco demandas que mais exigiram atenção do enfermeiro, a situação "pessoas demais em sua unidade de trabalho" obteve maior pontuação na UTI Geral, enquanto que as demandas "alto nível de barulho na unidade", "observar o sofrimento de um paciente", "execução de procedimentos que os pacientes experenciam como sendo dolorosos" e "ambiente de trabalho abarrotado de materiais e equipamentos" obtiveram maiores médias na UTI Pediátrica.

As demandas mais intensas para o enfermeiro em UTI apresentaram frequências elevadas no cotidiano das práticas das unidades pesquisadas, com destaque para a situação "alto nível de barulho na unidade" que apresentou a maior média da intensidade em uma escala de zero a $100\left({ }^{-} \mathrm{x}=72,1\right)$ e foi apontada por $91,1 \%$ dos enfermeiros como uma demanda presente em três dias ou mais em uma semana de trabalho na UTI (Tabela 1).

$\mathrm{Na}$ Tabela 2 apresentam-se as demandas que menos exigiram atenção do enfermeiro em terapia intensiva com médias inferiores a 60 quando considerada a relação entre frequência e intensidade.

As demandas com menores médias foram "conflito com um supervisor" ( $\mathrm{x}=6,1)$ e "ausência do médico da unidade quando um paciente morre" $\left({ }^{-} x=6,7\right)$, ambas do Domínio Comportamental. A situação "necessidade de dar orientação ao paciente", embora tenha apresentado a maior frequência em uma semana de trabalho, estando presente em três dias ou mais, conforme apontado por $35,1 \%$ dos enfermeiros, demandou pouco esforço desses profissionais com média da intensidade igual a 16,1.

\section{DISCUSSÃO}

Esta pesquisa possibilitou identificar as demandas de atenção do enfermeiro em terapia intensiva. Nas três unidades de terapia intensiva pesquisadas, as demandas que exigiram maior atenção do enfermeiro foram "alto nível de barulho na unidade", "observar o sofrimento de um paciente", "execução de procedimentos 
Tabela 2 - Situações de demandas que menos exigiram a atenção do enfermeiro considerando a média geral, as médias por UTI, a média da intensidade e a frequência relativa. São Luís, MA, Brasil, 2012

\begin{tabular}{|c|c|c|c|c|c|c|c|c|c|}
\hline \multirow[t]{3}{*}{ Situações de Demandas } & \multirow[t]{3}{*}{$\mathbf{D}^{*}$} & \multicolumn{4}{|c|}{$\begin{array}{l}\text { Pontuação da Demanda } \\
\text { (Frequência x Intensidade) }\end{array}$} & \multirow[t]{3}{*}{$\begin{array}{l}\text { Intensi- } \\
\text { dade }\end{array}$} & \multicolumn{3}{|c|}{ Frequência (\%) } \\
\hline & & \multirow[t]{2}{*}{ Geral } & UTI & UTI & UTI & & \multirow[t]{2}{*}{0 dia } & \multirow{2}{*}{$\begin{array}{c}1-2 \\
\text { dias }\end{array}$} & \multirow[t]{2}{*}{$\geq 3$ dias } \\
\hline & & & Ped & Neo & Geral & & & & \\
\hline $\begin{array}{l}\text { Paradas cardíacas tiveram que } \\
\text { ser atendidas }\end{array}$ & $\mathrm{F}$ & 58,3 & 60,4 & 36,1 & 78,4 & 34,3 & 43,2 & 47,5 & 8,9 \\
\hline $\begin{array}{l}\text { Falta de oportunidade de } \\
\text { compartilhar experiências } \\
\text { e sentimentos com outras } \\
\text { pessoas da unidade }\end{array}$ & $\mathrm{C}$ & 58,2 & 70,9 & 62,9 & 40,9 & 26,5 & 41,7 & 47,7 & 10,3 \\
\hline $\begin{array}{l}\text { Falta de oportunidade de falar } \\
\text { francamente sobre problemas } \\
\text { da unidade com outras pessoas } \\
\text { que nela trabalham }\end{array}$ & $\mathrm{C}$ & 53,3 & 78,9 & 49,7 & 31,4 & 29,7 & 45,3 & 47,7 & 6,7 \\
\hline $\begin{array}{l}\text { Necessidade de dar orientação } \\
\text { ao paciente }\end{array}$ & $\mathrm{P}$ & 48,8 & 16,9 & 29,1 & 100,3 & 16,1 & 43,9 & 20,7 & 35,1 \\
\hline $\begin{array}{l}\text { Falta de oportunidade } \\
\text { expressar sentimentos } \\
\text { relação aos pacientes }\end{array}$ & $\mathrm{C}$ & 39,2 & 77,4 & 16,8 & 23,3 & 16,8 & 57,9 & 31,4 & 10,3 \\
\hline $\begin{array}{l}\text { Discordância com relação ao } \\
\text { tratamento de um paciente }\end{array}$ & $\mathrm{C}$ & 38,9 & 80,4 & 16,1 & 20,1 & 23 & 54,5 & 39,5 & 3,3 \\
\hline $\begin{array}{l}\text { Informação inadequada de um } \\
\text { médico sobre a condição clínica } \\
\text { de um paciente }\end{array}$ & $\mathrm{C}$ & 37 & 92,5 & 0 & 18,5 & 18,1 & 61,1 & 32,2 & 6,7 \\
\hline $\begin{array}{l}\text { A morte de um paciente com } \\
\text { quem você desenvolveu um } \\
\text { relacionamento muito próximo }\end{array}$ & $\mathrm{P}$ & 32,9 & 0 & 29,8 & 68,9 & 21,5 & 66,7 & 33,3 & 0 \\
\hline $\begin{array}{l}\text { Incerteza com relação à } \\
\text { operação e funcionamento de } \\
\text { um equipamento especializado }\end{array}$ & $\mathrm{F}$ & 28,2 & 11,6 & 17,3 & 55,9 & 17,3 & 54,5 & 41,8 & 3,3 \\
\hline $\begin{array}{l}\text { Tomar uma decisão difícil com } \\
\text { relação a um paciente quando o } \\
\text { médico não está disponível }\end{array}$ & $\mathrm{P}$ & 26 & 0 & 11,3 & 66,6 & 16,6 & 71,1 & 28,9 & 0 \\
\hline $\begin{array}{l}\text { Ausência do médico no início } \\
\text { do atendimento de uma } \\
\text { emergência }\end{array}$ & $\mathrm{C}$ & 24,8 & 62,4 & 5,1 & 6,8 & 17,2 & 63,8 & 32,5 & 3,3 \\
\hline $\begin{array}{l}\text { Conversar com um paciente } \\
\text { sobre sua morte, que se } \\
\text { aproxima }\end{array}$ & $\mathrm{P}$ & 17,7 & 0 & 6,7 & 46,3 & 8,7 & 85,5 & 11,1 & 3,3 \\
\hline $\begin{array}{l}\text { Rodízios para outras unidades } \\
\text { que apresentaram um número } \\
\text { reduzido de funcionários }\end{array}$ & $\mathrm{F}$ & 17,6 & 0 & 8,3 & 44,4 & 6,8 & 88,9 & 7,8 & 3,3 \\
\hline $\begin{array}{l}\text { Dificuldade de trabalhar com } \\
\text { um determinado enfermeiro na } \\
\text { unidade }\end{array}$ & $\mathrm{C}$ & 16,8 & 30,9 & 0 & 19,5 & 10,4 & 76,7 & 23,3 & 0 \\
\hline Críticas de um supervisor & $\mathrm{C}$ & 16 & 29,8 & 11,1 & 7 & 12,7 & 64,9 & 34,8 & 0 \\
\hline Conflito com um médico & $\mathrm{C}$ & 15,9 & 42,6 & 0 & 5,1 & 9,9 & 82,2 & 17,8 & 0 \\
\hline Críticas de um médico & $\mathrm{C}$ & 15,7 & 39,5 & 0 & 7,7 & 8,9 & 80 & 16,7 & 3,3 \\
\hline $\begin{array}{l}\text { Ausência do médico da unidade } \\
\text { quando um paciente morre }\end{array}$ & $\mathrm{C}$ & 6,7 & 20 & 0 & 0 & 4,9 & 90 & 10 & 0 \\
\hline Conflito com um supervisor & $\mathrm{C}$ & 6,1 & 11,7 & 0 & 6,5 & 5,3 & 86,7 & 13,3 & 0 \\
\hline
\end{tabular}


que os pacientes experenciam como sendo dolorosos", "ambiente de trabalho abarrotado de materiais e equipamentos" e "pessoas demais em sua unidade de trabalho". Esta última demanda apresentou maior pontuação na UTI Geral em relação às outras duas unidades, enquanto as demais obtiveram maiores pontuações na UTI Pediátrica.

Analisando as situações de demandas separadamente por UTI, o ruído foi a principal causa de atenção do enfermeiro nas unidades pediátrica e neonatal e a segunda na UTI Geral.

Sob esse aspecto, exercer atividades em ambiente com constantes e excessivos ruídos é fator determinante para comprometimentos físicos, mentais e sociais nos profissionais de saúde, constituindo fontes de distração para o enfermeiro e dificultando a comunicação entre as pessoas, por implicar na compreensão equivocada de palavras ou frases, o que pode induzir os profissionais ao erro durante a prestação de cuidados, comprometendo a segurança do paciente $^{(6-7)}$. Outro estudo ${ }^{(8)}$ evidenciou que $\mathrm{o}$ ruído tem repercussões para além do campo profissional, pois mães de bebês internados em terapia intensiva deixaram de ficar mais tempo ao lado dos filhos por sentirem necessidade de afastar-se do ambiente da UTI devido ao ruído excessivo, o que compromete a interação e o fortalecimento do vínculo mãe-bebê.

Alguns estudos identificaram a terapia intensiva como ambiente de cuidado ruidoso ${ }^{(6,9-12)}$, indicando a necessidade de redução do ruído na perspectiva de tornar esse ambiente mais saudável e seguro para todos que atuam no cenário de terapia intensiva ${ }^{(13-16)}$.

Considerando as demandas que mais exigiram atenção do enfermeiro, no contexto da terapia intensiva é possível inferir que se trata de um ambiente complexo e repleto de fatores estressantes, pois o ritmo de trabalho na unidade é intenso e a todo o momento está presente a possibilidade de agravos e de morte, tendo também como participante contínuo o sofrimento do paciente e de suas famílias, a sobrecarga de trabalho, a execução de múltiplas e complexos atividades, a desorganização da unidade e do processo de trabalho, o quantitativo de pessoal insuficiente e o excesso de ruído, o que contribui para o desgaste do profissional ${ }^{(17)}$.

As situações de demandas que mais exigiram atenção dos enfermeiros nessas unidades estiveram relacionadas aos domínios
Ambiente Físico e Psicológico. Tais domínios desenvolvem situações associadas às instalações físicas do ambiente de trabalho, às emoções e preocupações, o que exige do enfermeiro maior capacidade de direcionar sua atenção para a prestação do cuidado. Soma-se a isso a execução de diversos procedimentos que podem causar dor e sofrimento nos pacientes. A demanda "observar o sofrimento de um paciente" destacase na enfermagem de terapia intensiva, pois a convivência com essa situação é diária e alia-se a outras que envolvem urgências, sofrimento e, não raras vezes, a perda do paciente. Trabalhar com o sofrimento, dor e presenciar a morte levam os enfermeiros a crescente estresse decorrente da atividade laborativa, podendo desencadear desgaste e sofrimento ${ }^{(18)}$.

Dessa maneira, ser capaz de executar procedimentos, principalmente os dolorosos, e observar a dor dos pacientes afeta psicologicamente os enfermeiros e requer dos mesmos habilidades para lidar com a simultaneidade das demandas físicas, biológicas, comportamentais e psicológicas.

As demandas com menores médias no Domínio Psicológico foram: "conversar com um paciente sobre sua morte, que se aproxima"; "tomar uma decisão difícil com relação a um paciente quando o médico não está disponível"; e "a morte de um paciente com quem você desenvolveu um relacionamento muito próximo". Embora a enfermagem seja uma das profissões de saúde mais suscetível ao estresse laboral devido ao contato direto, intenso e prolongado com o paciente, em especial na terapia intensiva, essas demandas exigiram menor atenção do enfermeiro. Falar sobre morte e a convivência com essa condição no processo de trabalho do enfermeiro em terapia intensiva pode ser apontado como evento esperado em virtude da condição clínica dos pacientes e ser considerada como transição e processo natural relacionado ao ciclo vital humano ${ }^{(19)}$. Por outro lado, a morte pode ser revelada como processo difícil que envolve sofrimento e desgaste emocional desse profissional ou ainda traduzir-se em conhecimento limitado para lidar com o mesmo, pois sua formação é voltada às ações técnicas e práticas e pouco embasamento sobre o campo das necessidades de pacientes e famílias em processo de finitude ${ }^{(20)}$.

As demandas do Domínio Comportamental referem-se ao relacionamento interpessoal do enfermeiro com os demais membros da equipe, incluindo sua possibilidade de expressar-se ${ }^{(2)}$. As 
médias encontradas neste domínio foram baixas quando comparadas com as encontradas nos outros domínios. Quando avaliadas as médias de cada UTI, identifica-se, especialmente na UTI Neonatal, que várias dessas demandas obtiveram pontuação nula. Nesse Domínio, a baixa média para a situação "falta de oportunidade de expressar sentimentos em relação aos pacientes" pode revelar a ausência de espaços dialógicos e interativos de verbalização, relatos e discussões sobre as implicações do cotidiano do trabalho na dimensão emocional e laboral do enfermeiro.

As situações que menos exigiram atenção do enfermeiro referiram-se às demandas provenientes de conflitos ou críticas, demonstrando que as equipes dos três setores pesquisados apresentam bom relacionamento interpessoal com os demais profissionais e chefias. Sob esse aspecto, enfatiza-se que a hierarquia e as relações entre os profissionais e destes com seus superiores (supervisões, chefes, coordenadores) são importantes ferramentas para o mundo do trabalho, capazes de interferir na motivação pessoal dos trabalhadores e na satisfação dos mesmos no cotidiano das suas práticas, com repercussões positivas que expressam a qualidade do ambiente laboral.

\section{CONCLUSÃO}

A pesquisa permitiu identificar as demandas que mais exigiram atenção do enfermeiro intensivista considerando o contexto da terapia intensiva pediátrica, neonatal e geral. Apesar das especificidades de cada contexto, as demandas apresentaram médias diferentes e se concentraram nos Domínios Ambiente Físico e Psicológico. As demandas do Domínio Comportamental apresentaram menores médias e, dessa maneira, foram as que menos exigiram a atenção dos enfermeiros. Isso chamou atenção, pois são demandas que dizem respeito em especial aos processos interativos do enfermeiro com pacientes e demais profissionais.

As demandas de atenção identificadas expõem a necessidade de melhorias institucionais que reduzam o esforço mental e o desgaste físico dos enfermeiros, evitando-se assim a fadiga, para que esse profissional não tenha prejudicada a sua capacidade de direcionar a atenção durante a prestação do cuidado em terapia intensiva. Nessa perspectiva, as situações de demandas relacionadas ao ambiente são passíveis de serem resolvidas ou amenizadas a curto prazo. Por outro lado, a gestão de recursos humanos deveria favorecer a verbalização e a escuta qualificada dos problemas relacionados ao domínio Psicológico como forma de promover a saúde ocupacional dos enfermeiros e dos demais profissionais.

Destes resultados, emergiram algumas proposições que não puderam ser desenvolvidas devido ao tipo do estudo, das quais: os enfermeiros de UTI tem valorizado a alta densidade tecnológica e investido menos nas relações e interações com os usuários? O cuidado de enfermagem no contexto da terapia intensiva tem como maior suporte a realização de procedimentos e centrado na doença? Mas, talvez uma abordagem qualitativa possa explicar as razões para médias baixas nesse domínio, pois as interações permeiam as relações de cuidado e profissionais e deveriam ser intensas no contexto da UTI, condições que sugerem a realização de outras pesquisas tendo como objeto o mundo vivido do enfermeiro e terapia intensiva.

\section{REFERÊNCIAS}

1. Santos LSC, Guirardello EB. Demandas de atenção do enfermeiro no ambiente de trabalho. Rev. LatinoAm Enfermagem. [Internet] 2007; 15(1) [acesso em 09 jul 2010]. Disponível: http://dx.doi.org/10.1590/S010411692007000100005

2. Guirardello EB. Adaptação cultural e validação do instrumento demandas de atenção dirigida. Rev. Esc. Enferm. USP. [Internet] 2005; 39(1) [acesso em 09 jul 2010]. Disponível: http://dx.doi.org/10.1590/S008062342005000100010

3. Reis CK, Guirardello EB, Campos CJG. O indivíduo renal crônico e as demandas de atenção. Rev. Bras. Enferm. [Internet] 2008; 61(3) [acesso em 22 set 2012]. Disponível: http://dx.doi.org/10.1590/S003471672008000300010

4. Gonçalves LA, Padilha KG. Fatores associados à carga de trabalho de enfermagem em Unidade de Terapia Intensiva. Rev. Esc. Enferm. USP. [Internet] 2007; 41(4) [acesso em 21 ago 2012]. Disponível: http://dx.doi. org/10.1590/S0080-62342007000400015

5. Roscani ANCP, Guirardello EB. Demandas de atenção no ambiente de trabalho e capacidade de direcionar atenção do enfermeiro. Rev. Latino-Am. Enfermagem. [Internet] 2010; 18(4) [acesso em 21 ago 2012]. Disponível: http://www.scielo.br/pdf/rlae/v18n4/ pt_17.pdf

6. Sampaio Neto RA, Mesquita FOS, Paiva Junior MDS, Ramos FF, Andrade FMD, Correia Junior MAV. Ruídos na unidade de terapia intensiva: quantificação e percepção dos profissionais de saúde. Rev. bras. ter. intensiva [Internet] 2010; 22(4) [acesso em 21 set 
2015].Disponível:http://dx.doi.org/10.1590/S0103507X2010000400010

7. Moisés MS, Medeiros SM, Freitas JAC. Influência do contexto de trabalho na saúde dos profissionais de enfermagem de uma unidade de terapia intensiva em um hospital universitário. Enferm. glob. [Internet] 2013; 12(32) [acesso em 24 ago 2015]. Disponível: http://scielo.isciii.es/scielo.php?pid=S169561412013000400011\&script=sci_arttext\&tlng=pt

8. Grecco GM, Tsunemi MH, Balieiro MMFG, Kakehashi TY, Pinheiro, EM. Repercussões do ruído na unidade de terapia intensiva neonatal. Acta Paul Enferm. [Internet] 2013; 26(1) [acesso em 24 ago 2015]. Disponível: http:// dx.doi.org/10.1590/S0103-21002013000100002

9.Aurélio FS, Tochetto TM. Ruído em uma Unidade de Terapia Intensiva Neonatal: mensuração e percepção de profissionais e pais. Rev. Paul. Pediatr [Internet] 2010; 28(2) [acesso em 21set 2015]. Disponível: http:// dx.doi.org/10.1590/S0103-05822010000200006

10. Cardoso MVLML, Chaves EMC, Bezerra MGA. Ruídos e barulhos na unidade neonatal. Rev. Bras. Enferm. [Internet] 2010; 63(4) [acesso em 21set 2015]. Disponível: http://dx.doi.org/10.1590/S003471672010000400010

11. Nogueira MFH, Ramos EG, Peixoto MVM. Identificação de fontes de ruído e de pressão sonora em unidade neonatal. Rev.Enferm. UERJ [Internet] 2011; 19(4) [acesso em 20set 2015]. Disponível: http:// www.facenf.uerj.br/v19n4/v19n4a02.pdf

12. Peixoto PV, Balbino FS, Chimirri V, Pinheiro EM, Kakehashi TY. Ruído no interior das incubadoras em unidade de terapia intensiva neonatal. Acta Paul. Enferm. [Internet] 2011; 24(3) [acesso em 20 set 2015]. Disponível: http://dx.doi.org/10.1590/S010321002011000300009

13. Marques IR, Souza AR. Tecnologia e humanização em ambientes intensivos. Rev. Bras. Enferm. [Internet] 2010; 63(1) [acesso em 20set 2015]. Disponível: http:// dx.doi.org/10.1590/S0034-71672010000100024

14. Daniele D, Pinheiro EM, Kakehashi TY, Balbino FS, Balieiro MMFG. Reduzindo o nível de pressão sonora da unidade de terapia intensiva neonatal: estratégias adotadas pelos profissionais de saúde.Rev. Min. Enferm. [Internet] 2011; 15(2)[acesso em 20 set 2015]. Disponível: http://www.reme.org.br/artigo/detalhes/24

15.Zamberlan-Amorim NE, Fujinaga $\mathrm{Cl}$, Hass VJ, Fonseca LMM, Fortuna CM, Scochi CGS. Impact of a participatory program to reduce noise in a neonatal unit. Rev. Latino-Am. Enfermagem [Internet] 2012; 20(1)[acesso em 20set 2015]. Disponível: http://dx.doi. org/10.1590/S0104-11692012000100015

16. Oliveira FMCSN, Paiva MB, Nascimento MAL,
Rezende VM, Silva AS, Silva CRL. Noise levels in a pediatric intensive care unit: an observational and correlational study. OBJN [Internet] 2013; 12(2) [acesso em 20 set 2015]. Disponível: http://dx.doi. org/10.5935/1676-4285.20134043

17. RodriguesTDF. Fatores estressores para a equipe de enfermagem da unidade de terapia intensiva. Rev. Min. Enferm. [Internet] 2012; 16(3) [acesso em 24 ago 2015]. Disponível: http://reme.org.br/content/imagebank/ pdf/v16n3a18.pdf

18. Martins JT, Robazzi MLCC. O trabalho do enfermeiro em unidade de terapia intensiva: sentimentos de sofrimento. Rev. Latino-Am. Enfermagem [Internet] 2009; 7(1) [acesso em 24 ago 2015]. Disponível: http:// dx.doi.org/10.1590/S0104-11692009000100009

19. Santos MA, Hormanez M. Atitude frente à morte em profissionais e estudantes de enfermagem: revisão da produção científica da última década. Ciênc. Saúde Coletiva [Internet] 2013; 18(9) [acesso em 20 set 2015]. Disponível: http://dx.doi.org/10.1590/S141381232013000900031

20. Hercos TM, Vieira FS, Oliveira MS, Buetto LS, Shimura CMN, Sonobe HM. O trabalho dos profissionais de enfermagem em Unidade de Terapia Intensiva na assistência ao paciente oncológico. Rev Bras Cancerologia 2014; 60(1) [acesso em 22 set 2015]. Disponível: http://www.inca.gov.br/ rbc/n_60/v01/pdf/08-revisao-literatura-o-trabalhodos-profissionais-de-enfermagem-em-unidadesde-terapia-intensiva-na-assistencia-ao-pacienteoncologico.pdf 